\title{
Prótese Total Imediata
}

Luiz Fernando Walber. C.D.*

\section{INTRODUÇÃO}

O grande problema a ser enfrentado, quando da indicação de próteses totais, reside no fato dos pacientes relutarem em permanecer sem seus dentes enquanto aguardam a reparação tecidual e óssea. Esse fator de ordem psicológico e estético tem levado tanto pacientes quanto profissionais a utilizar a prótese imediata como solução para esses casos.

Podemos conceituar a prótese total imediata como sendo aquela prótese total que será instalada imediatamente após a extração dos dentes remanescentes e nesse mesmo ato clínico. É um aparelho cuja confecção ante.cede as extrações dentárias.

\section{VANTAGENS E DESVANTAGENS}

Apenas o fator estético já justifica a indicação das PTI quando está indicada a eliminação total dos dentes. Além desse, existem inúmeras vantagens que nos levam a optar pela realização deste tipo de trabalho, tornando-o uma rotina de consultório:

1. evita a perda da dimensão vertical

2. previne traumatismo sobre a ATM

3. impede o colapso labial e o afundamento das bochechas
4. possibilita a musculatura envolvida, a continuidade de sua atividade normal

5. evita transtornos fonéticos

6. permite a continuidade das atividades sociais

Uma das maiores desvantagens da PTI é o tipo de paciente que lidamos. Um paciente totalmente despreparado quanto aos problemas e limitações inerentes ao uso de próteses totais, e cuja cooperação posterior dependerá não apenas da qualidade do nosso trabalho, mas também da atitude psicológica do paciente.

Alguns fatores também podem ser encarados como desvantagens, por isso devem ser lembrados e, podem até ser motivo para a não realização do trabalho:

1. trabalho adicional

2. custo adicional

3. não há possibilidade de realizar provas estéticas

4. menor ajuste

5. perda temporária da fixação

\section{INDICAÇÃO E CONTRA-INDICAÇÃO}

A indicação deste tipo de trabaIho está na dependência da idade e estado geral de saúde, permitindo que se realize as intervenções cirúrgicas necessárias; no desejo do paciente para se submeter a este tipo de atencimento e que tenha condições psicológicas favoráveis.
Embora Sahri afirme que o único paciente para 0 qual se contra-indica a dentadura imediata é o que se submete a radioterapia pois, 0 uso de uma dentadura poderia gerar uma osteoradionecrose; existem casos que esse diagnóstico exige cautela e outros que é totalmente contra-indicados.

No primeiro grupo colocaríamos os acidentes anatômicos como más oclusões; retenções ósseas como tórus e exostoses; mucosa hiperplásica e inserções musculares e freios hipertrofiados.

No segundo grupo estariam os pacientes, como afirma Tamaki, com doenças mentais, pacientes diabéticos, cardícos, hemofflicos, histéricos, muito idosos com saúde geral debilitada.

\section{EXAME CLÍNICO}

Deve ser minucioso. A idade é um fator importante, assim como os transtornos de origem psíquisa.

Devemos nos ater a parte dentada, verificando a posição dos dentes na arcada, a sua oclusão com os antagonistas (Figura 1).

Sobre a parte desdentada, devemos observar o tamanho do rebordo

* Interno da Disciplina de Prótese Total, FO-UFRGS. 


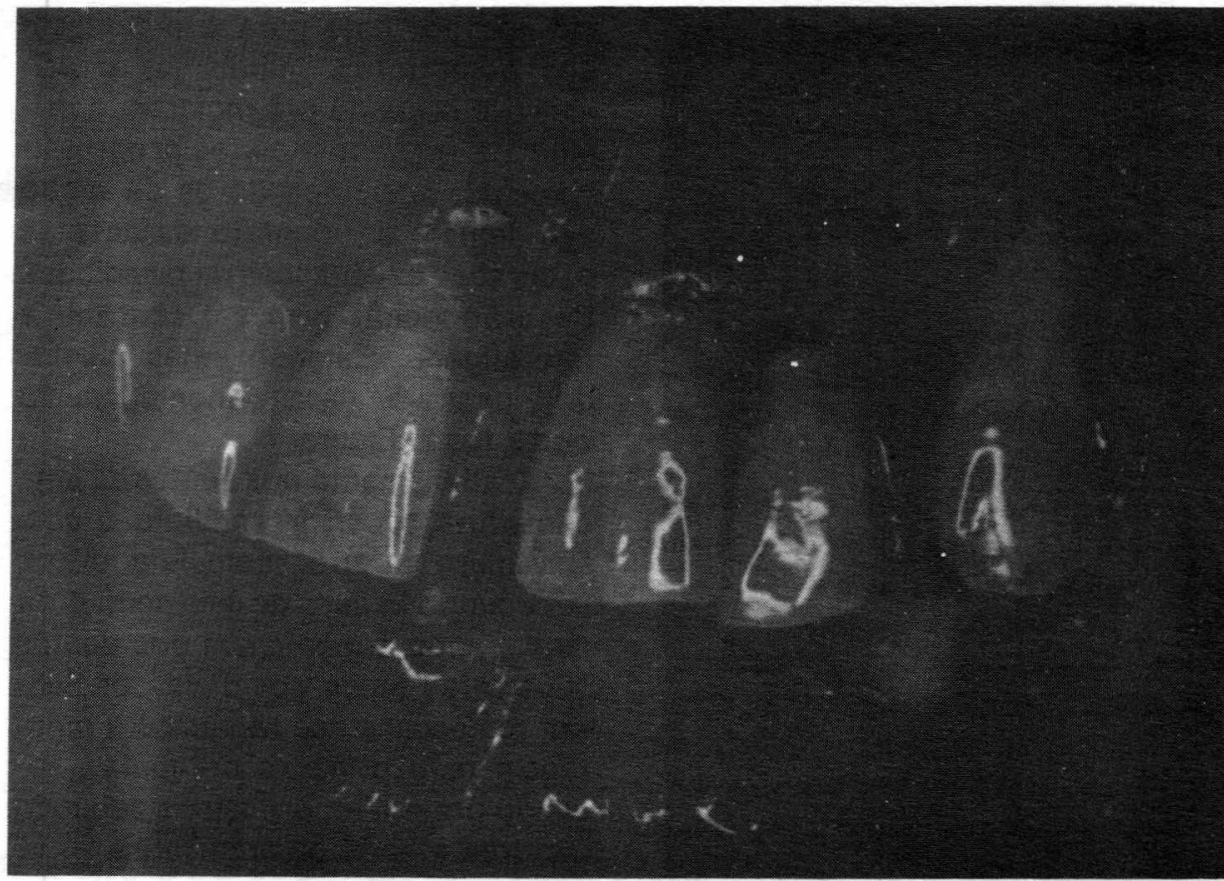

FIGURA 1 - Caso clínico indicado para dentadura imediata.

alveolar, sua compressibilidade e coloração da mucosa alveolar de revestimento.

Radiografias que nos mostrem o estado de toda a boca, devem ser tomadas; modelos de estudo devem ser montados em um articulador para auxiliar o diagnóstico e possibilitar um prognóstico.

Todos os dados devem ser registrados numa ficha clínica para consultas posteriores.

\section{MOLDAGEM}

\section{Moldagem Preliminar}

O material mais adequado é o alginato, pois alguns dentes ainda estão presentes. Com uma moldeira de estoque, em tamanho adequado obtém-se a moldagem da área chapeável e dos dentes antagonistas.

Sears indica que se deve marcar com um lápis tinta a linha de inserção dos tecidos, área que requerem alívios, especialmente zona de rugas palatinas, a linha do limite posterior da dentadura e a área de travamento posterior. Estas marcas seriam transferidas à moldagem preliminar.

De qualquer forma devemos nos certificar que a moldagem tenha re- coberto toda a área chapeável e que os dentes e áreas retentivas tenham sido reproduzidas.

O modelo será confeccionado com gesso pedra. Após o recorte dos excessos das margens será duplicado mantendo-se, assim, o registro permanente da forma dos dentes e de suas posições em relação ao rebordo. Isto nos possibilta posterior avaliação do trabalho realizado.

\section{Moldagem Final}

A moldagem para uma dentadura imediata, requer a confecção de uma moldeira individual especial que, de acordo com a técnica, será ou não fracionada. As técnicas variam em função da escolha do material de moldagem que poderá ser a associação de godiva, pasta zinco-enólica ou alginato, ou godiva e um elastômero.

\section{Técnicas}

1. Confecção de uma moldeira individual com rodete de cera que recubra toda a área chapeável, isto inclui também os dentes remanescentes, sobre os quais é criado um alívio em cera para que não haja retenção mecânica. Faz-se o re- corte da moldeira e o vedamento periférico com godiva em bastão. A moldagem final é feita somente com alginato.

2. Confecção de uma moldeira individual igual a anterior. Após o recorte da moldeira e o vedamento periférico, abre-se uma janela sobre a área dentada. Cobre-se a moldeira com pasta zinco-enólica para a moldagem de toda a região edentada. Recobre-se novamente esta janela com cera para a complementação da moldagem com alginato (Figuras 2 e 3 ).

3. Confecção de uma moldeira individual que recubra também a área dentada com seus respectivos alivios. Recorte da moldeira para a confecção do vedamento periférico. Após a aplicação do adesivo, cobre-se a moldeira com mercaptana ou silicona.

$\mathrm{Na}$ introdução da moldeira devese observar a direção dos dentes. Quando houver muita retenção junto aos dentes 0 alginato tende a romper-se, tornando necessário a eliminação destas retenções com o uso de cera nos espaços interdentários.

$\mathrm{Na}$ moldagem mista de alginato e pasta zinco-enólica ocorre com freqüência a superposição destes materiais, deixando uma zona de transição com muitas irregularidades ou com a formação de um bordo muito grosso e na região e na região dos dentes, não se tem uma delimitação perfeita.

Saizar sugere o uso dos elastômeros, por suas vantagens sobre os demais materiais, permitindo melhor ajuste sobre a mucosa e um melhor vedamento com a godiva. Não necessita de apoios especiais para sua centralização.

Feita a moldagem deve-se remover as partes de material sem apoio da moldeira, encaixar e vazar o gesso pedra.

\section{RELAÇÕES \\ MAXILO-MANDIBULARES}

O método utilizado para a montagem dos modelos no articulador é idêntico ao que é utilizado na con- 


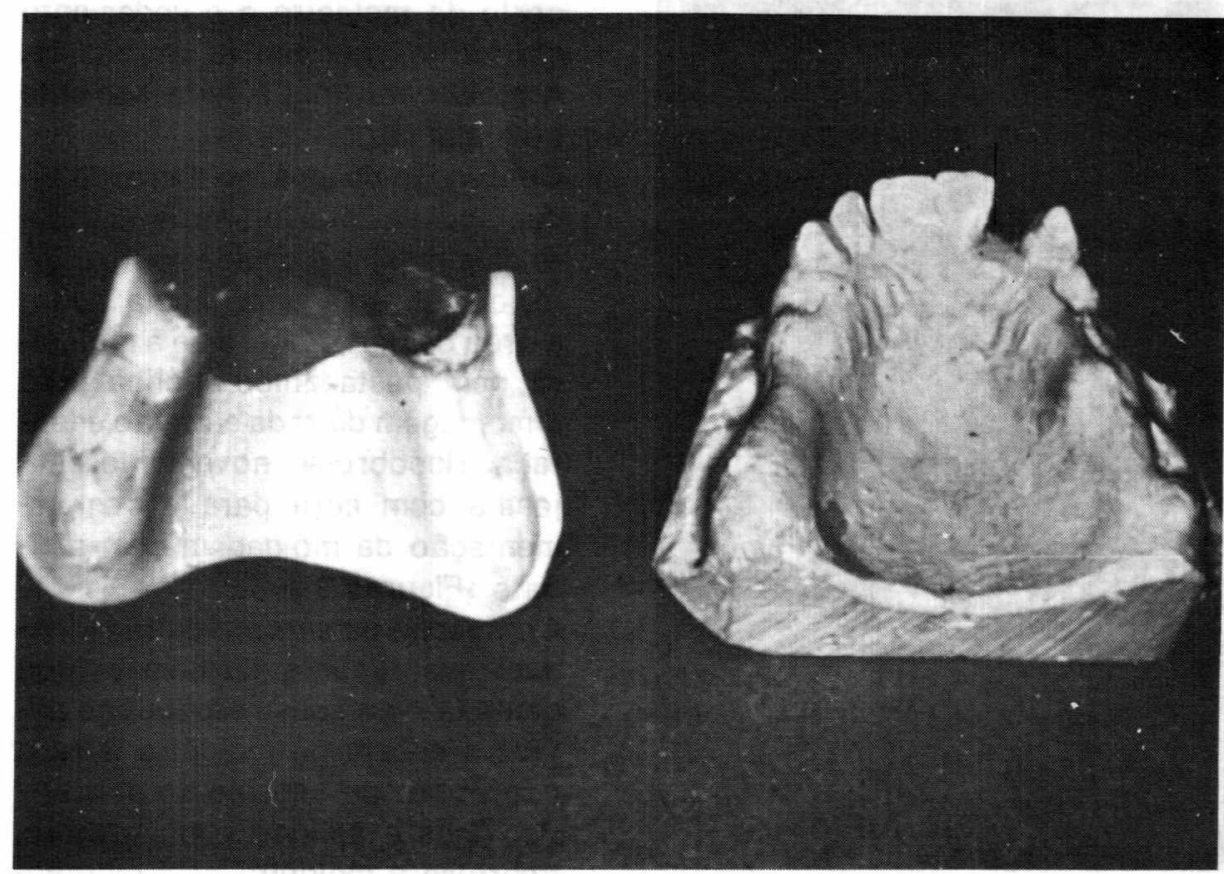

mo-nos por este para a montagem dos posteriores. Instalamos o primeiro o segundo pré-molares, e primeiro e segundo molares progressivamente, posicionando-os de modo que fiquem em contato durante as excur sões excêntricas da mandíbula. Deverão ocluir bem em cêntrica e lateralidade. Estando estes alinhados, passa-se para a montagem do outro lado (Figura 4).

$\mathrm{O}$ alinhamento dos dentes de uma dentadura superior imediata e uma dentadura inferior completa difere um pouco. No caso de uma dentadura dupla, após a montagem dos dentes superiores tendo como guia os dentes remanescentes seguimos a montagem pelo primeiro pré-molar, segundo pré-molar, primeiro e segundo molares e após os anteriores.

FIGURA 2 - Moldeira individual com alivio em cera.

fecção de dentaduras totais. devemos ter em mente que a presença de dentes, nem sempre nos dá uma correta dimensão vertical. Poderão apresentar abrasão considerável ou mobilidade. Confecciona-se uma placa em acrílico de rápida polimerização, bem adaptada ao modelo. Com um rodete de cera cuja altura deverá recuperar a dimensão vertical. Neste rodete fixamos uma forquilha que juntamente com a placa articular será levada à boca, quando então fazemos o registro com o arco facial para fixação do modelo superior no articulador. Determinada esta relação, recupera-se o rodete de cera utilizado e sobre este colocase uma delgada camada de cera utilizada para a obtenção da relação cêntrica. Leva-se o paciente a posição mais retruída da mandíbula, sem forçar e pede-se que oclua até atingir a dimensão vertical por nós determinada. Este registro deve ser repetido várias vezes até que se tenha certeza de que coincidiu com a relação cêntrica. $E$ assim montamos 0 modelo inferior no articulador.

\section{MONTAGEM DOS DENTES}

A presença de dentes remanescentes facilitará a escolha dos den-

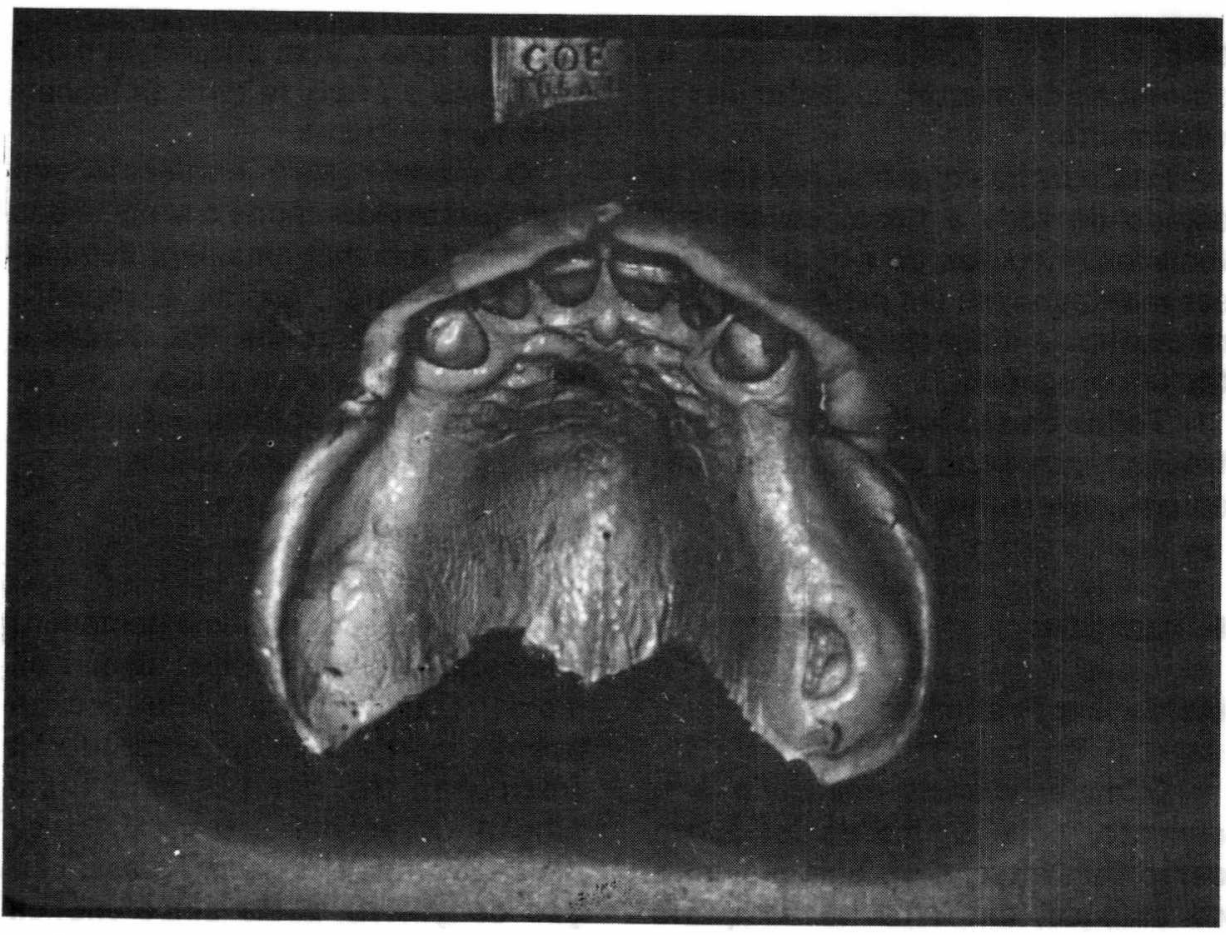

FIGURA 3 - Moldagem da área edentada com pasta zinco-enólica e da área dentada com alginato.

tes da prótese imediata. Os dentes posteriores deverão se harmonizar em tamanho com os pré-molares e molares antagonistas. Os dentes anteriores deverão imitar a forma, tamanho e cor dos dentes remanescentes.

Os caminhos superiores naturais mais ou menos posicionados, guia-
Finalmente mede-se a profundidade das bolsas periodontais para saber até onde pode-se recortar a superfície labial do modelo sem ter que reduzir depois o osso alveolar. Esta medida é registrada com um lápis sobre o modelo para que se desgaste o mesmo após a remoção dos dentes de gesso. Preferencialmente 
deve-se evitar a alveolectomia na região anterior pos isso, prefere-se o uso de dentes de resina que permitam o desgaste, quando nos deparamos com um processo proeminente.

O método mais simples de realizar a substituição é através da remoção de dentes intercalados, no modelo de gesso pedra ou, segundo Saizar corta-se os dentes de um hemi-arco ou até mesmo todos os anteriores de uma única vez. A montagem neste caso fica a critério do profissional.

Articulados os dentes, passamos para o encerramento e inclusão da dentadura (Figura 5). No momento em que abrimos o muflo para a eliminação da cera, devemos moldar o modelo com suas características defini tivas para a confecção em resina transparente de termo polimerização, de uma placa guía cirúrgica. Esta placa orientará o cirurgião ao eliminar os locais de maior compressão no momento da regularização do rebordo.

\section{ENTREGA DA DENTADURA E INSTRUÇÕES}

Tome alguns cuidados especiais ao entregar a dentadura imediata, já que esta será instalada sobre tecidos anestesiados que sofreram traumatismo cirúrgico e ainda poderão sofrer algumas alterações. A assepsia de toda a região inclusive da dentadura deve ser realizada.

Instalada a prótese poderá ocorrer:

1. falta de retenção - se for pequena com pó adesivo pode-se solucionar, mas de for maior convém que se proceda um reembasamento imediato com um material acondicionador de tecido, com um elastômero ou um acrílico de autopolimerização. Não esquecer de proteger a ferida cirúrgica antes de proceder este ato.

2. problemas oclusais - com papel articular e pedras abrasivas busque uma oclusão balanceada.

3. problemas estéticos - de um modo geral, somente com a confecção

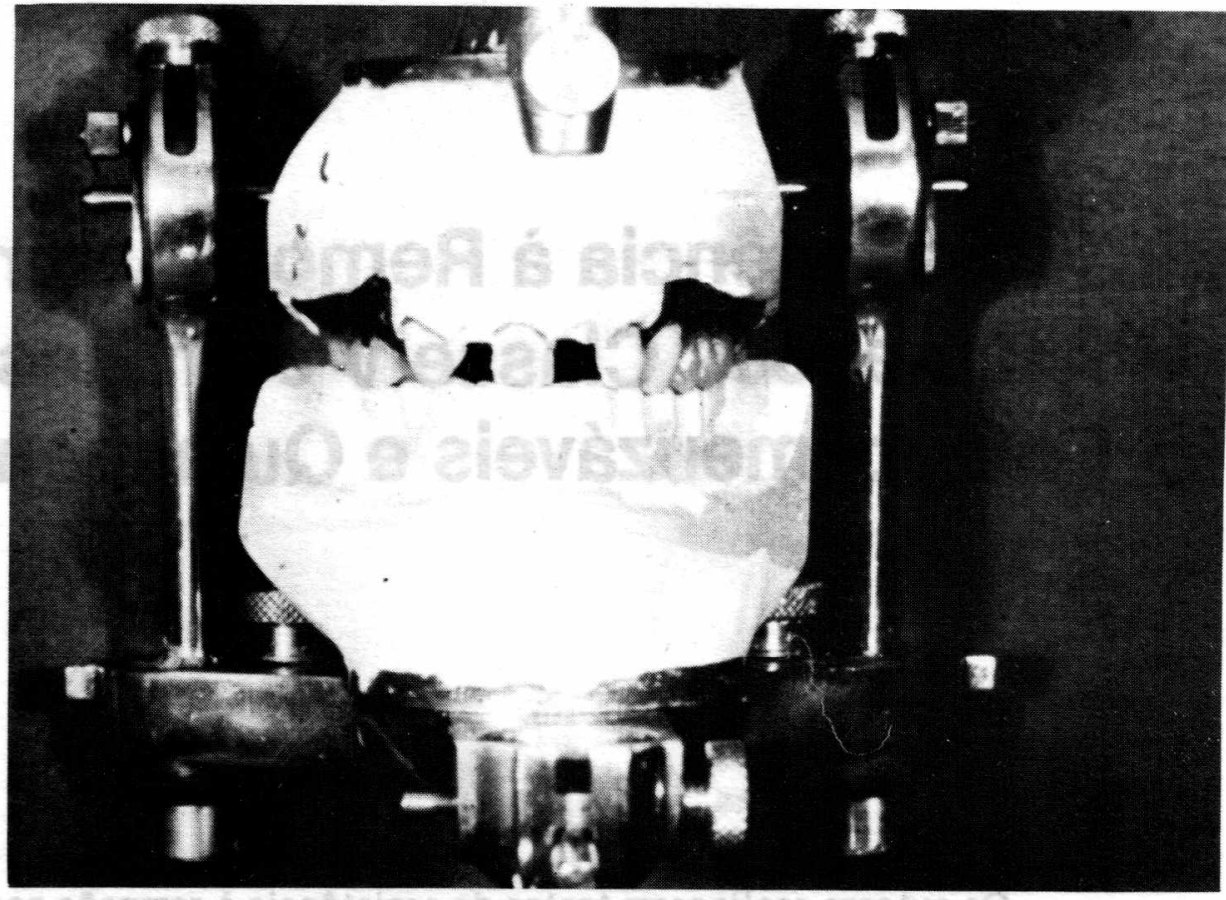

FIGURA 4 - Modelos articulados em articulador com montagem dos dentes posteriores.

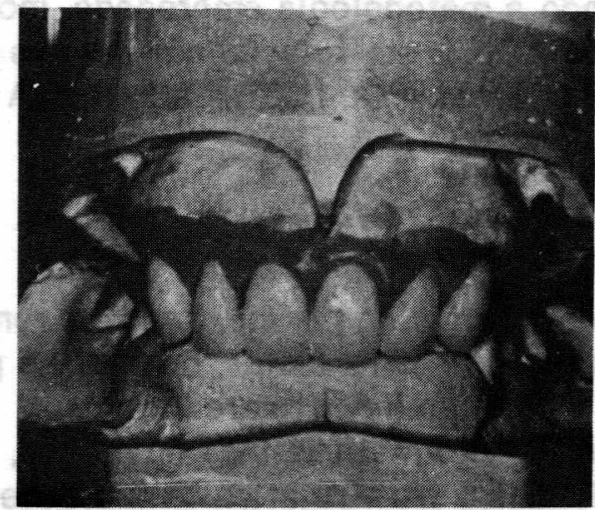

FIGURA 5 - Dentes anteriores articulados mantendo a estética original do paciente.

de um novo aparelho protético é que se conseguirá solucionar.

As instruções ao paciente são as mesmas dadas ao portador de uma prótese mediata. Também convém que este não a remova da boca por 24 a 48 horas, quando retornará ao consultório para uma reavaliação e para que sejam feitos os alivios das regiões traumáticas.

Por ser um aparelho de transição, fica ainda mais difícil determinar o tempo de sua duração. Mas é consenso geral de que o primeiro reembasamento, preferivelmente seja realizado o mais tarde possível.

\section{BIBLIOGRAFIA}

1. CERVEIRA NETTO, H. Prótese Total Imediata. Pancast Editorial. São. Paulo, 1987.

2. DONITE, Saide Sarckis. Novos Métodos $e$ Técnians. Livraria e Editora Santos, 1984.

3. NAGLE, R.J. \& SEARS, V.H. Prótesis Dental. Barcelona, Ed. Toray, 1965. cap. 19, p.447-459.

4. SAIZAR, Pedro. Prostodoncia Total. Buenos Aires, Ed. Mundi, 1972. cap. 24, p.456.

5. SCHLOSSER, R.O. \& GEHL, D.H. Protesis Completa. Buenos Aires, Ed. Mundi, cap. 22, p.423.

6. SHARRY, J.J. Prostodoncia Dental Completa. Barcelona, Ed. Toray, 1977, cap. XVIII, p.297.

7. TAMAKI, Tadachi. Dentaduras Completas. São Paulo, Ed. Sarvier, 1974. 2.ed. cap. XVIII, p.231. 